\title{
Analyzing the Influencing Factors of Economic Fluctuations in the Era of Big Data
}

\author{
Xiaoliang Xiong (iD \\ College of Applied Technology, Wuhan Technology and Business University, Wuhan 430065, Hubei, China \\ Correspondence should be addressed to Xiaoliang Xiong; xiongxiaoliang@wtbu.edu.cn
}

Received 17 December 2021; Revised 6 January 2022; Accepted 7 January 2022; Published 25 January 2022

Academic Editor: Tongguang $\mathrm{Ni}$

Copyright (C) 2022 Xiaoliang Xiong. This is an open access article distributed under the Creative Commons Attribution License, which permits unrestricted use, distribution, and reproduction in any medium, provided the original work is properly cited.

\begin{abstract}
In view of the problems of poor correlation and poor calculation accuracy of the existing factors affecting economic fluctuations, this paper designs a new method for analyzing the factors affecting economic fluctuations based on the characteristics of the era of big data. First, after determining the factors influencing the economic fluctuations in the era of big data, the calculation method of key impact indicators is clarified. Then, the entropy law method is used to assign a weight value to the index, and the set is formed after the index is gathered. Then, the EM algorithm is used to assign the expected value to the data in the set. Finally, the set of influencing factors of the economic fluctuations is taken as input information, and the correlation evaluation model of influencing factors of economic fluctuations is constructed by the Monte Carlo method to complete the analysis of the influencing factors. The experimental results show that the correlation coefficient of influencing factors of economic fluctuations in the era of big data analyzed in this paper is high and the calculation accuracy of influencing factors is high, which proves the feasibility of this method.
\end{abstract}

\section{Introduction}

With the further deepening of the reform of the socialist economic system and the continuous improvement of the reform of the socialist market economic system, the means of national macrocontrol have played a more and more important role in the development of the social economy $[1,2]$. The reform of China's market economic system has led China's economy into a new stage, and China's economy has begun to have economic cycle fluctuations with the characteristics of a market economy. Western economists have put forward many economic theories and economic models to explain the reasons for the economic cycle fluctuations in various countries under the market economy system [3]. Some economists have tried to monitor, analyze, and predict the fluctuation of the economic cycle since the beginning of the twentieth century. Cyclical fluctuations are only temporary deviations from equilibrium. The interior of the market economy system is very stable, and the power of the market can ensure the rapid recovery of the equilibrium state [4]. Economists at that time advised the administration not to intervene in the cyclical fluctuations of the economy. Because of this, the research on the economic cycle did not attract enough attention from economists at that time.

From a practical point of view, in countries dominated by the market economy, macroeconomic performance has become an important indicator to measure the administrative ability of the authorities. Therefore, the administrative authorities are trying to reduce the fluctuation range of the economic cycle and prolong the expansion stage of the economic cycle through macroeconomic policies, so as to make the economy in low unemployment stable operation under high growth rate and moderate inflation level [5-7]. The emphasis on macroeconomic performance and the enthusiasm to implement macroeconomic policies make the administrative authorities strive to seek the help of economists. At the same time, economists also hope that their research can affect the decision-making of the administrative authorities. This relationship also further stimulates economists' enthusiasm for the research of economic cycle issues. Globalization has provided a huge driving force for the world economy. Capital, labor, technology, natural 
resources, and markets have been reoptimized and allocated. The economies of various countries are increasingly interconnected and interdependent, and the international division of labor and international exchange has been expanded and deepened. However, due to the different economic systems and political and social environments of countries all over the world, there are constant collisions, competition, and infiltration in the process of economic globalization, which makes the economic situation complex and changeable. In addition, in recent decades, global environmental change, climate change, economic, social, and political emergencies, and other issues are superimposed with economic issues $[8,9]$.

The analysis of the influencing factors of economic fluctuations is an overall comprehensive and systematic analysis and judgment of the macroeconomy. It is the final judgment of macroeconomic development through the comprehensive sorting of many statistical data, and it is the progress and leap in the understanding of large complex statistical data. It is the supervision and measurement of a series of indicators representing the process and current situation of economic activities, and based on the understanding of the regularity of the process and the monitoring results, it puts forward an alarm for the possible turning points and major changes in economic activities in the future [10]. According to the analysis of the influencing factors of economic fluctuations, it is very important to adjust the effective strategies of economic development in real time. Therefore, relevant studies have analyzed the factors of economic fluctuation under the background of the big data era and achieved some results.

In the current study, relevant scholars analyzed the factors affecting the internal structure of the economy from the static perspective and found that the enterprises' profitability, debt-paying ability, development ability, operation ability, operation scale, industrial-chain added value, and other factors will have an impact on their capital structure [11]. Other scholars analyzed the changes of capital structure in recent years and found through model analysis that the adjustment speed of capital structure target was slow in the process of economic fluctuations. With the development of capital market, financing methods of listed companies will change, and excessive financing phenomenon exists to a certain extent in equity and debt financing [12]. However, in the existing studies, the impact of economic fluctuations without considering the background of the times is systematically analyzed, leading to poor accuracy of index correlation and impact degree calculation.

Therefore, based on the existing literature research, this paper studies the influencing factors of economic fluctuation in the era of big data. By constructing the index system of influencing factors of economic fluctuation, calculating the weight of each index, and predicting the risks in the index of economic fluctuation factors, this paper provides a certain theoretical basis for the analysis of future economic fluctuation. The technical route of this paper is as follows.

(1) After clarifying the index system of influencing factors of economic fluctuations in the era of big data, the calculation methods of key influencing factor indexes are established through different algorithms.

(2) The weight values of different indexes are determined by entropy law.

(3) The clustering algorithm is used to gather the indicators into a set, then the EM algorithm is used to give the expected value of the data in the set, and then the Monte Carlo method is used to construct the correlation evaluation model of the influencing factors of economic fluctuation. The set of influencing factors of economic fluctuation is used as the input of the model to complete the analysis of influencing factors of economic fluctuation in the era of big data.

\section{Construction and Analysis of Index System of Influencing Factors of Economic Fluctuation}

2.1. Index System of Influencing Factors of Economic Fluctuation. With the advent of the era of big data, the economic industrial chain is becoming more and more complex, and the characteristics of economic cycle fluctuation will be reflected in the data changes of some economic indicators [13-15]. In the economic fluctuation impact index system, according to the time sequence differences of indicators, they are usually divided into leading indicators, consistent indicators, and lagging indicators [16-19]. The leading indicator refers to the indicator that the occurrence time of its cycle turning point is stably ahead of the corresponding turning point of the overall market cycle and changes ahead of the overall market fluctuation in time. The reason it can predict the trend of economic prosperity is that it has a leading causal relationship with economic activities. Consistency index refers to the index whose cycle turning point appears almost simultaneously with the overall turning point of the market, and the fluctuation in time is consistent with the overall economy. Such indicators have two functions: to describe the boom state of the current economic operation. By analyzing the time difference between the consistent index and the leading index, the time of the overall cycle turning point can be estimated from the turning point of the leading index. The process of constructing the index system of influencing factors of economic fluctuations is shown in Figure 1.

According to the previously mentioned analysis, this paper constructs the key index system of influencing factors of economic fluctuations in the big data era according to the current actual situation. The overall indicators are shown in Table 1.

According to the indicators of different sectors determined, it lays a data foundation for the analysis of influencing factors of economic fluctuations under the background of big data era.

Among them, the calculation method of the determined index affects its analysis. Therefore, the calculation method of the index in the previously mentioned determined influencing factor index system will be clarified. 


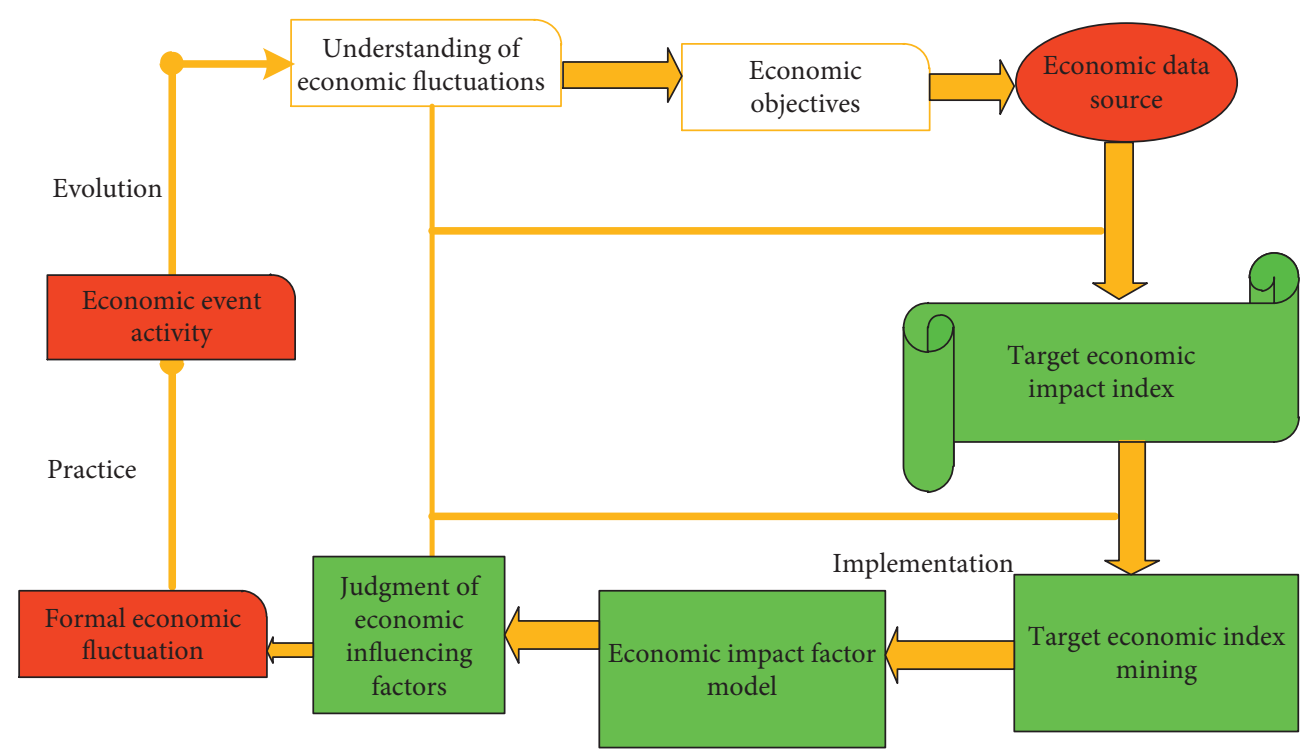

FIgURE 1: Construction of index system of influencing factors of economic fluctuation.

TABLE 1: Index system of influencing factors of economic fluctuations in the era of big data.

\begin{tabular}{|c|c|c|}
\hline Level 1 index & Secondary indicators & Detailed \\
\hline \multirow{2}{*}{$\begin{array}{l}\text { Market economy } \\
\text { structure }\end{array}$} & \multirow{2}{*}{$\begin{array}{c}\text { Economic and industrial structure } \\
\text { Rationalizing the economic and industrial } \\
\text { structure }\end{array}$} & Structural balance \\
\hline & & Market marketization of industrial structure \\
\hline \multirow[b]{2}{*}{ Economic market system } & Economic volatility indicators & \multirow{2}{*}{$\begin{array}{l}\text { GDP and the national economic level } \\
\text { Individual economy, collective economy and private } \\
\text { economy }\end{array}$} \\
\hline & Economic marketization & \\
\hline $\begin{array}{l}\text { Economic policy } \\
\text { regulation }\end{array}$ & $\begin{array}{l}\text { Macroeconomic policy } \\
\text { Microeconomic policy } \\
\text { External demand }\end{array}$ & $\begin{array}{l}\text { Subjective financial policy } \\
\text { We will fine-tune economic policies } \\
\text { External output and input, etc. }\end{array}$ \\
\hline
\end{tabular}

\subsection{Index Calculation of Influencing Factors of Economic Fluctuation}

2.2.1. Changes in Industrial Structure. The change of industrial structure is the change of the proportion structure of various industries in the national economy, which reflects the adjustment of macroeconomy after the change of internal and external environment, and different industries in the national economy respond differently to the fluctuation of economic cycle. From the perspective of economic dynamic evolution, the change of industrial structure can be measured from the two dimensions of industrial structure rationalization and industrial structure modernization [20-23].

The fluctuation of industrial economic structure affects the fluctuation of the overall economy in the era of big data, which is a key factor that cannot be ignored in social and economic development. Because the structural rationality of different industries needs more factors to be calculated, this paper only focuses on the rationality and irrationality of industrial structure. Since the founding of the People's Republic of China, especially since the reform and opening up, great changes have taken place in China's industrial structure. The proportion of China's three industries in GDP is $15.1 \%, 45.9 \%$, and $390 \%$ in 2019 and $11.3 \%, 486 \%$, and
$401 \%$ in 2020 . Since then, there has been an upward trend of changes every year. As can be seen from the figure, China's secondary industry is still the leading industry, accounting for the largest proportion, but its proportion has been relatively stable, fluctuating between $41 \%$ and $49 \%$. The proportion of the primary industry shows a downward trend year by year, from $28.2 \%$ in 2011 to $11.3 \%$ in 2020 , a decrease of nearly 17 percentage points. The proportion of tertiary industry shows a gradual upward trend, from $23.9 \%$ in 2011 to $40.1 \%$ in 2020 , an increase of 17 percentage points. The overall change trend is shown in Figure 2.

The rationalization of industrial structure also refers to the balance degree of industrial structure, which indicates the reasonable degree of the proportion between various industrial departments in the process of social production, or the balance degree of demand and supply structure of various industrial departments with input-output relationship [24]. This is a key factor in economic fluctuations in the context of big data. Structural deviation degree or structural imbalance degree is generally used to measure $[25,26]$, and its expression is as follows:

$$
R=\sum_{i=1}^{n}\left|\frac{x_{i} / x_{j}}{x_{i}}-1\right| .
$$




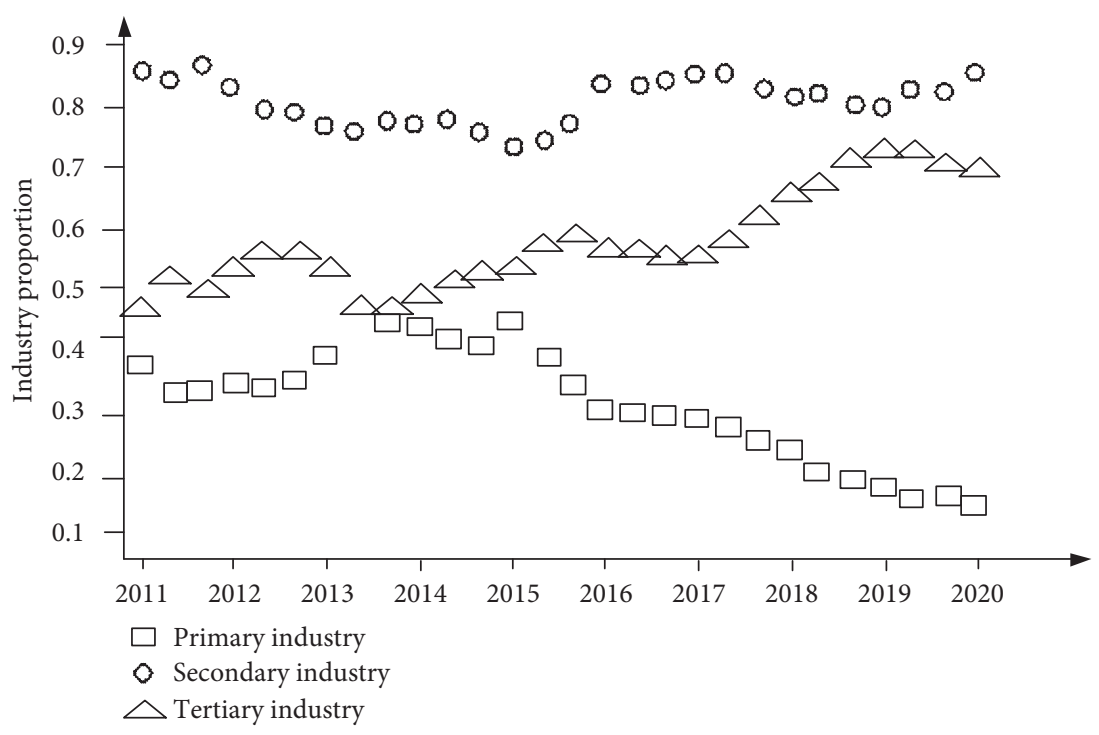

FIgURE 2: Change trend of proportion of three industries from 2011 to 2020.

Among them, $i$ is the industry category, and $i \in n, R$ indicates the imbalance of the industrial structure, $x_{i}$ is the added value, $x_{j}$ is the number of employees, and $x_{i} / x_{j} / x_{i}$ indicates the labor productivity.

When $R=0$, the labor productivity of each industrial sector is just equal to that of the whole economy, and the whole society realizes the optimal allocation of resources. However, in the real economy, this is an ideal state, there is always a structural deviation, and the greater the $R$ value, the more unreasonable the industrial structure [27]. However, this indicator ignores the relative importance of different industries in the national economy. Therefore, in order to reflect this, Theil index is used to measure the deviation degree of industrial structure [28], which is expressed as

$$
T R=\sum_{i=1}^{n}\left(\frac{x_{i}}{x_{j}}\right) \ln \left(\frac{x_{i}}{x_{j}} / x_{j}\right),
$$

where TR represents the imbalance degree of industrial structure.

Formula (2) shows that when the labor productivity of each industrial department is equal to the overall labor productivity, the economy is balanced and the TR is zero. The greater the value of the TR, the more unreasonable the industrial structure.

2.2.2. Calculation of GDP Growth Rate. When studying and analyzing the economic cycle fluctuation, the growth rate of GDP is generally taken as the index to measure the economic fluctuation. However, since the time series data are often nonstationary series data containing trend characteristics, it is necessary to deal with the original data and eliminate the trend components contained in the time series data, and the obtained periodic fluctuation part is taken as the series data of economic fluctuation. In practical application, HP filtering method has strong adaptability, so it is widely used in separating trend components and periodic fluctuations in time series. Therefore, this method is also used in this paper [29].
HP filtering method is based on the principle of symmetrical data moving average method. Its advantage is that it can eliminate the trend components and keep the periodicity of the original data unchanged; that is, the data does not have phase shift [30]. The specific method of HP filtering method is to decompose the time series data into growth trend components and periodic fluctuation components:

$$
v_{i}=a_{i}+b_{j}
$$

In the formula, $a_{i}$ is the trend component and the $b_{j}$ component of periodic fluctuations. Since the trend component in the time series changes smoothly, it can be obtained by minimizing the following formula:

$$
z=\sum_{i=1}^{t}\left(a_{i}-b_{j}\right)^{2}+\gamma\left[a_{i+}+b\right]_{j}-\left(a_{i}-b_{j}\right)^{2},
$$

where $\gamma$ is the smoothing parameter, in a practical application, and the general value is 100 .

Due to the rapid rise of GDP, it can be seen from the previously mentioned analysis that when the proportion of the primary industry decreases and the proportion of the secondary industry increases more than the proportion of the primary industry to become the leading industry of the whole economy, the economy has strong volatility; when the proportion of the primary industry and the secondary industry decreases at the same time and the proportion of the tertiary industry continues to rise to a certain extent, the whole economy will show a more stable trend. The change trend is shown in Figure 3.

2.2.3. Economic Policy Indicators. Since the reform and opening up, China's market economic system has been continuously improved, but the government has little influence on the operation of the economy. Control and prediction still have an important impact. The government will use various economic policies to regulate the 


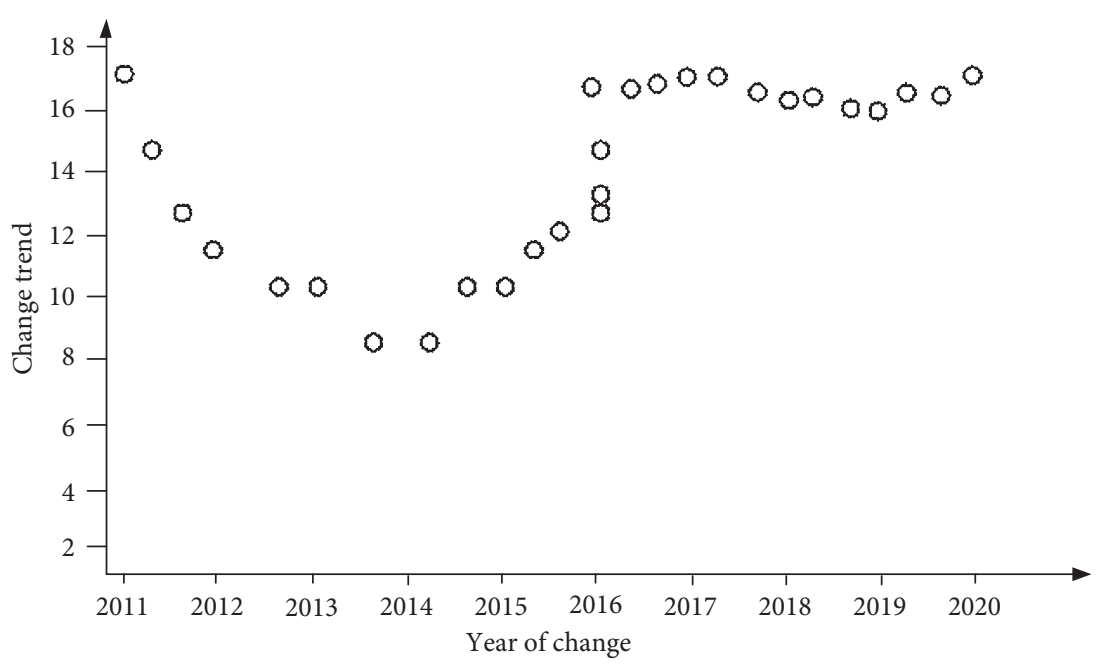

FIGURE 3: General trend of GDP change in 10 years.

economy, which plays a very important role in the fluctuation of the economic cycle. Among them, fiscal policy and monetary policy are the two most important policy tools for the government to regulate and control economic operation. Fiscal policy is included, and a macroeconomic policy status index, including monetary policy and fiscal policy, is established to measure the tightness of macroeconomic policy [31]. The monetary policy status index is expressed by the weighted average of percentage point changes of interest rate and exchange rate, and its formula is as follows:

$$
C=e_{i}\left(E-E_{0}\right)+e_{j}\left(H-H_{0}\right) .
$$

Among them, $H$ indicates the actual interest rate, $H_{0}$ is the initial interest rate, $E$ indicates the effective exchange rate, $E_{0}$ is the initial exchange rate, and $e_{i}$ and $e_{j}$ indicate the corresponding weight of the actual interest rate and the effective exchange rate, respectively.

2.2.4. External Demand. Since the reform and opening up, with the expansion and deepening of opening to the outside world, China's trade openness has gradually improved. Foreign demand plays a very important role in China's economy, and the change of foreign demand directly affects the fluctuation of domestic economy. Here, the change of external demand is expressed by the export growth rate:

$$
G_{t}=\frac{p_{t}}{p_{t-1}-1} \times 100 \%
$$

Among them, $p_{t}$ represents the total export of the current year; $p_{t-1}$ represents the total export of the previous year.

Opening to the outside world includes the opening of current account and capital account. China's capital account has not been fully opened.

Foreign direct investment (FDI) has been liberalized, but other financial projects are still under control. Here, it is expressed by the growth rate of FDI:

$$
F_{i}=\frac{f_{i}}{f_{i-1}-1} \times 100 \% .
$$

Among them, $f_{i}$ represents the amount of FDI; $f_{i-1}$ represents the amount of FDI in the previous year.

In recent years, the change trend of external demand indicators is shown in Figure 4.

According to the previously mentioned analysis, the relationship structure between the indicators of influencing factors and economic fluctuations can be determined, which is more complex, as shown in Figure 5.

To sum up, based on the analysis of the characteristics of the big data era, this study constructs the index system of influencing factors of economic fluctuations and defines the calculation method of key influencing factor indicators through different algorithms, so as to lay a foundation for subsequent research.

\section{Weight Calculation and Correlation Evaluation of Influencing Factors}

3.1. Weight Calculation of Influencing Factors of Economic Fluctuations in the Era of Big Data. There are many datasets in the influencing factors of economic fluctuations in the era of big data, so it is impossible to calculate one by one, which will increase the complexity of the research. Therefore, this paper calculates the weight of the key influencing index factors constructed as previously mentioned. The most commonly used diversification index is entropy index. The concepts and viewpoints related to nature defined in the entropy law, such as equilibrium state, maximum value, and uniform distribution, attract regional researchers to explore the measurement of economic diversity in this regard. Entropy is calculated as follows:

$$
K=\sum_{i=1}^{n} q_{i j} \ln \frac{1}{q_{i j}} .
$$

Among them, $q_{i j}$ represents industry $j$ employment in the share of total employment. The entropy index increases with 


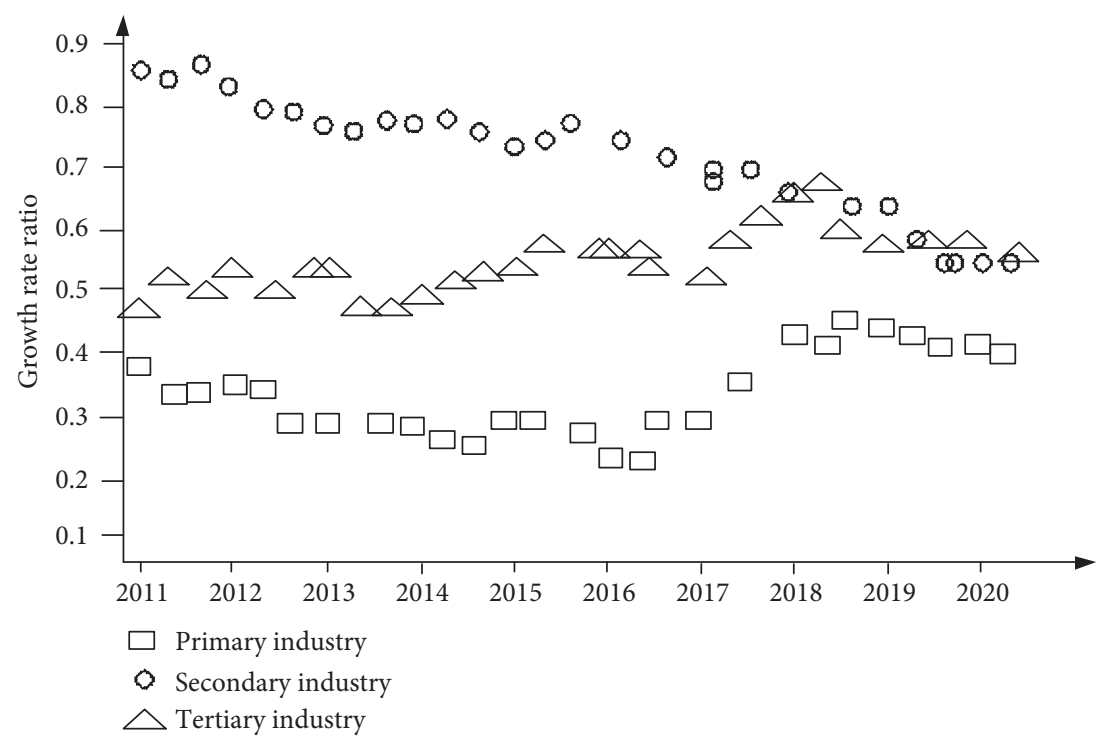

FIGURE 4: Variation trend of external demand indicators.

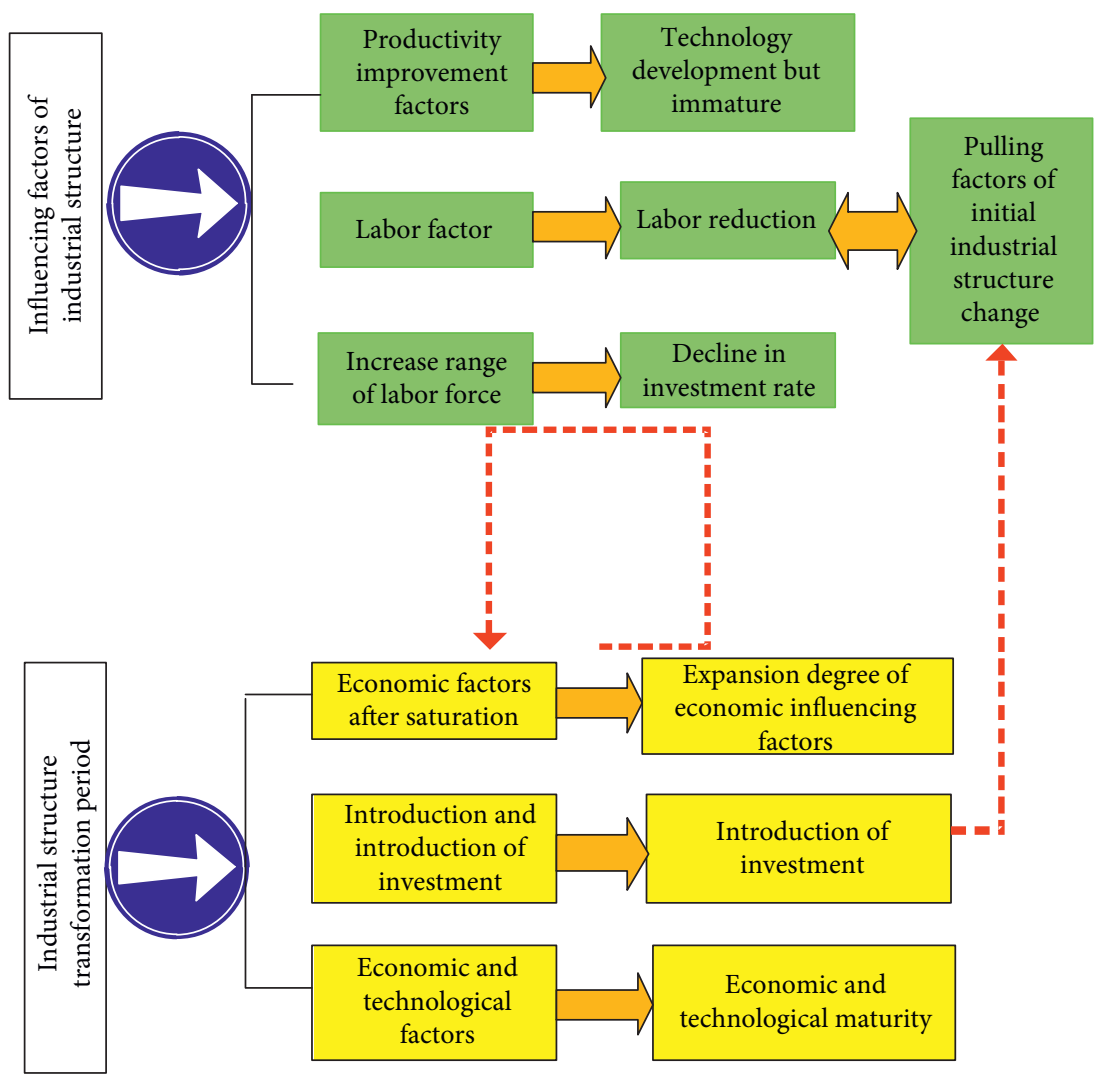

FIGURE 5: Structural diagram of the relationship between influencing factor indicators and economic fluctuations.

the growth of the number of departments in a region and the average of each sector. If the regional economy is completely evenly distributed among $N$ industries, the entropy index reaches the maximum $\ln \left(1 / q_{i j}\right)$, representing complete diversification. Instead, if a region economy is concentrated in a certain industry, $q_{i j}=1$ and the entropy index value is 0 .

The construction of entropy also determines its superiority in use; that is, it can be easily calculated by using percentage distribution data.
General diversification measures can only integrate the number and size uniformity of sectors but cannot distinguish the degree of intersectoral differences and linkages. However, the differences and intersectoral linkages in various sectors must have different effects on economic growth and its fluctuations. Using the additivity of entropy, the previously mentioned entropy is decomposed into relevant diversification and irrelevant diversification: 


$$
K^{\prime}=\sum_{i=1}^{n} q_{i j} \sum_{k=1}^{n} \sum_{k=n}^{m}\left[q_{i j}\left(\ln \frac{1}{p}\right)\right] .
$$

Because the similarity of influencing factors of different economic indicators is low, the entropy index is defined as irrelevant diversity. The similarity of the same data is high, and the entropy calculated by taking the small department in the same large department as the unit is defined as correlation diversity.

Set the number of departments, namely, $k=1,2,3, \ldots, K(K=21) ; j$ is the number of small departments in the $K$ large division. The first item in the formula-right is the related diversity (RV), which is the weighted sum of the lower entropy indicators composed of the share of the small sectors in the large sector, with the weight of

$$
R_{i}=\sum_{k=1}^{n} p_{j}
$$

Among them, $R_{i}$ is the weight of the index; $p_{i}$ is the coefficient of the lower entropy.

\subsection{Correlation Evaluation Model of Influencing Factors of} Economic Fluctuation. According to the weight of the factors affecting economic fluctuations in the big data era determined as previously mentioned, to determine whether the economic indicators in this paper are effective indicators, it is necessary to determine whether the previously mentioned indicators are important factors affecting the economic fluctuations in the big data era according to the calculation of weight.

First, through the clustering algorithm, the influencing factors of economic fluctuations in the era of big data with large weight value are gathered into a set, and then, the data in the set are effectively collected as data input for the subsequent research of correlation evaluation model.

The steps of K-means algorithm are as follows: first, $\mathrm{K}$ samples of fluctuation influencing factors are randomly selected as the representative objects of $\mathrm{K}$ clusters. Calculate the distance between other samples and the center of $\mathrm{K}$ known clusters and add each sample to its nearest cluster. After assigning clusters to all samples, recalculate the average value of each cluster as the representative object of the cluster. Repeat the previously mentioned process until the samples in each cluster do not change. In practice, the sum of square errors is usually used as the objective function. As shown in the formula, when the value of the objective function does not change or changes below the set threshold, the final clustering result is obtained; that is,

$$
\sigma=\sum_{i=1}^{k} \sum_{j=1}^{k}\left|w-c_{i}\right|^{2},
$$

where $\sigma$ is the sum of squared error for all samples in the data set, and $w$ represents a given single sample, and $c_{i}$ is the mean of cluster $C$.
Then, the effective training is performed on the data in the set of economic fluctuations in the clustered big data era. The desired assignment was made to each fluctuation influencing factor index using the EM algorithm. The parameters of the mixed model were initially estimated and then repeated until convergence. Step $E$ is called the expectation step, calculating the membership probability of each object according to the current parameter; the $M$ step is called the maximization step, and the probability calculated by step $E$ is used to update the parameter estimation. The probability of object $\mathrm{O}$ belonging to cluster $\mathrm{C}$ can be calculated by

$$
T\left(t \in c_{i}\right)=\frac{T\left(c_{i}\right) t\left(t \in c_{i}\right)}{\sum T\left(c_{i}\right) t\left(t \in c_{i}\right)} \log T\left(c_{i}\right) \varepsilon\left(t \in c_{i}\right),
$$

where $T\left(t \in c_{i}\right)$ represents obeying the mean, and $T\left(c_{i}\right) t\left(t \in c_{i}\right)$ represents the positive distribution of variance and the expected assignment coefficient.

Third, build the correlation evaluation model of influencing factors of economic fluctuations in the era of big data. In constructing the model, it is necessary to determine the occurrence probability of the correlation of the influencing factors of economic fluctuations. From the definition of probability, the probability of an event can be estimated by the frequency of the event in a large number of tests. When the sample size is large enough, it can be considered that the frequency of the event is its probability. Therefore, a large number of random sampling can be carried out for the random variables affecting its reliability, and then, these sampling values can be substituted into the functional function formula group by group to determine whether the structure fails, and finally, the failure probability of the structure can be obtained. The Monte Carlo method is based on this idea.

Assuming a statistically independent random variable $X_{i}=1,2,3 \ldots k$, the corresponding probability density function is $f_{x}$ and the functional number formula is $Z=g\left(x_{1}\right.$, $\left.x_{2}, \ldots, x_{k}\right)$. First, the value of group $\mathrm{N}$ random numbers $x_{1}$, $x_{2}, \ldots, x_{k}$ is generated according to the corresponding distribution of each random variable, and the correlation evaluation model of economic fluctuation influencing factors in the era of big data constructed is

$$
\min \delta\left(X_{i}\right)=\frac{1}{n}|w|^{2}+\frac{k}{l} \sum\left(s_{i}+s_{j}\right),
$$

where $\delta$ represents the penalty coefficient, $s_{i}$ represents the control fitting parameter, and $s_{j}$ represents the dual coefficient.

Finally, input the set of economic fluctuation influencing factors in the trained big data era, and output the index correlation of the determined influencing factors; namely,

$$
L(x)=\sum_{i=1}^{k}\left(s_{i}+s_{j}\right) \phi+b,
$$

where $\phi$ represents the correlation regression coefficient and $b$ represents the nonlinear relationship index. 
To sum up, in the correlation evaluation model of economic fluctuation influencing factors constructed in this study, first, the clustering algorithm is used to gather the indicators into a set. After giving the index expectations, the Monte Carlo method is used to construct the correlation evaluation model of economic fluctuation influencing factors, so as to complete the analysis of economic fluctuation influencing factors in the era of big data.

\section{Experimental Analysis}

4.1. Experimental Scheme Design. In order to verify the effectiveness of this method in evaluating the influencing factors of economic fluctuation, an experimental analysis is carried out. In the experiment, a medium-sized and large enterprise in a certain place was taken as the research object. According to the changes of the enterprise's economic development in the past year in 2020, the key factors affecting the enterprise's economic change were set in the experiment, quantified, and evaluated according to the method setting. The parameters in the experiment are shown in Table 2.

4.2. Experimental Index Design. According to the previously mentioned experimental scheme, the comparative experiment is carried out using the comparative method. In the experiment, by comparing the methods of this paper and literatures [6] and [7], the correlation of the analysis index system and the accuracy of the calculation of the influencing factors are the experimental indexes. In order to ensure the accuracy of the experiment, the results obtained in the experiment have been iterated for many times.

4.3. Analysis of Experimental Results. In the experiment, first, the correlation of this method and the methods of literatures [6] and [7] on the sample economic data index system is analyzed. The correlation in the experiment takes the correlation coefficient as the research object. In the experiment, the value range of the coefficient is [0-1]. The larger the coefficient, the higher the impact of the determined economic impact index and fluctuation change. The experimental results are shown in Figure 6.

By analyzing the experimental results in Figure 6, it can be seen that the correlation of the sample economic data index system determined by the methods of this paper and literatures [6] and [7] is different. It can be seen from the experimental results that the correlation coefficient of the economic data impact indicators determined by this method is high, up to 0.92 , and the lowest is about 0.80 . The correlation coefficient of the economic data impact indicators determined by the methods of literatures [6] and [7] fluctuates more. Compared with this method, the fluctuation range of this method changes less, and the correlation is higher. This is because the calculation methods of key influencing factor indicators are defined through different algorithms. On this basis, the entropy law method is used to determine the weight value of indicators, and the clustering algorithm is used to gather the influencing factor indicators
TABle 2: Experimental parameter design.

\begin{tabular}{lc}
\hline Parameter & Data \\
\hline Number of evaluation indicators/piece & 100 \\
Value range of interference coefficient & {$[0,1]$} \\
Test interval/S & 0.5 \\
Iterations/time & 100
\end{tabular}

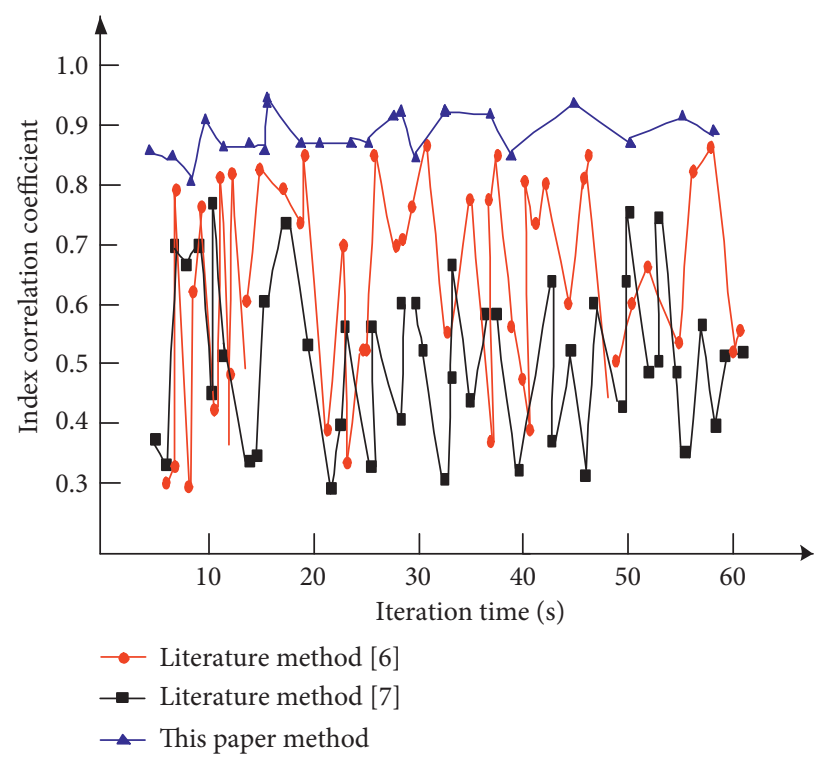

Figure 6: Correlation analysis of economic data index system determined by different methods.

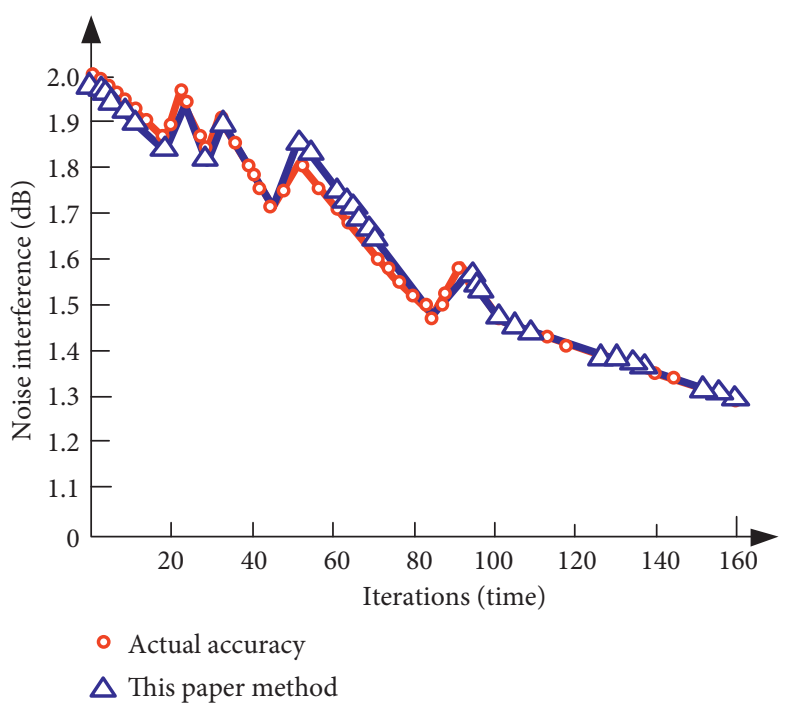

FIgURE 7: Precision results of sample economic impact index calculation by this method.

of economic fluctuation in the era of big data into a set to construct the influencing factor indicators of economic fluctuation, which improves the effectiveness of this method.

In the experiment, the accuracy of this method and the methods of literatures [6] and [7] on the calculation of sample economic impact indicators is analyzed. The results are shown in Figures 7-9. 


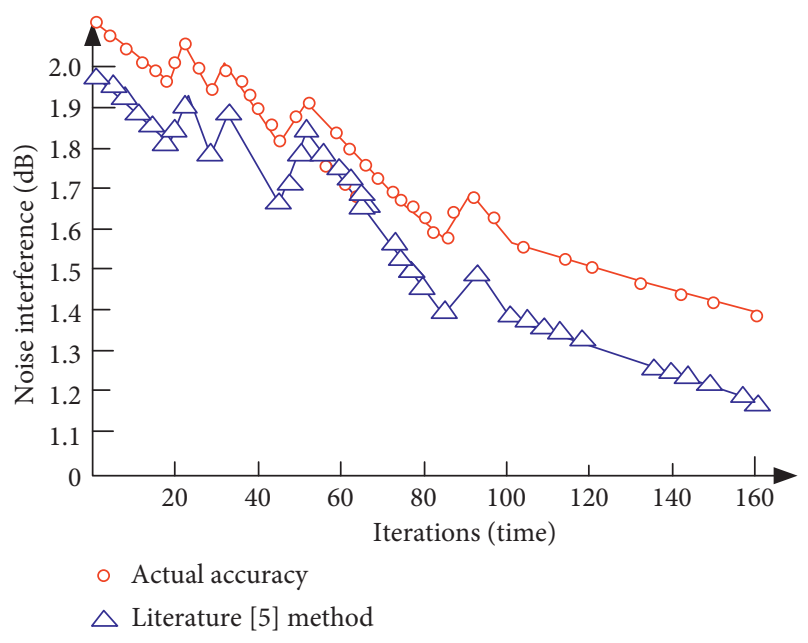

FIgURE 8: Precision results of sample economic impact index calculation by the method of literature [6].

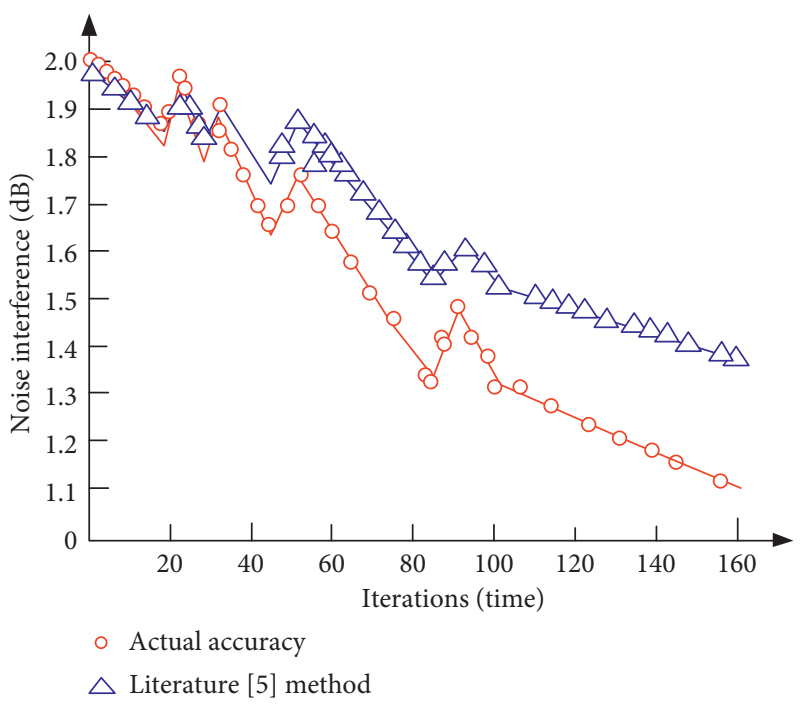

FIGURE 9: Precision results of sample economic impact index calculation by the method of literature [7].

By analyzing the experimental results in Figures 7-9, it can be seen that there are some differences in the accuracy of sample economic impact index calculation using the methods in this paper and literatures [6] an [7]. Among them, the accuracy of the sample economic impact index calculated by the method in this paper is relatively consistent with the actual calculation results. The accuracy of the sample economic impact index calculated by the methods in literatures [6] and [7] is different from the ideal value, and there are certain fluctuations. In contrast, the calculation accuracy of this method is better.

\section{Conclusion}

(1) With the continuous change of the economic environment, the index system of the existing economic fluctuation influencing factor analysis methods is less relevant. Therefore, this paper studies the economic fluctuation influencing factor analysis method in the new big data era. After clarifying the index system of influencing factors of economic fluctuations in the era of big data, the entropy law method is used to determine the weight values of different indicators. Then, the indexes are clustered into a set by clustering algorithm, and the EM algorithm is used to give the expected value of the data in the set. Finally, the Monte Carlo method is used to build the correlation evaluation model of the influencing factors of economic fluctuations to complete the analysis of the influencing factors of economic fluctuations in the era of big data.

(2) The experimental results show that the correlation coefficient of the influencing factors of economic fluctuations in the big data era analyzed by this method is high, the calculation accuracy of the influencing factors is high, and it is feasible.

(3) In the next research, we will further refine this analysis method, consider applying it to different fields, and expand the applicability of the analysis method.

\section{Data Availability}

The dataset can be accessed upon request.

\section{Disclosure}

This paper is the phased research result of 2021 universitylevel scientific research project "Research on World Skills Competition Freight Forwarding Project Based on Hubei Commercial Logistics Industry Chain" (project no.: S2021002).

\section{Conflicts of Interest}

The authors declare that they have no conflicts of interest.

\section{References}

[1] B. H. Wang, "Research on the influencing factors of in the era of big data of cross-border electricity development," Journal of Jiamusi Vocational Institute, 2014.

[2] L. Sun and L. Zhao, "Library, Research on the influencing factors of the E-commerce data quality," Journal of Modern Information, vol. 12, 2019.

[3] S. Xiong and B. Ye, "Analysis on the development path of smart city in the era of big data," in Proceedings of the IEEE 4th International Conference on Big Data Analytics (ICBDA), 1518 March 2019.

[4] H. Shuai, J. Fang, X. Ai, T. Yufei, W. Jinyu, and H. Haibo, "Stochastic optimization of economic dispatch for microgrid based on approximate dynamic programming," IEEE Transactions on Smart Grid, vol. 10, no. 3, pp. 2440-2452, 2018.

[5] A. Alessandretti, A. P. Aguiar, and C. N. Jones, "An input-tostate-stability approach to economic optimization in model predictive control," IEEE Transactions on Automatic Control, vol. 991 page, 2017. 
[6] J. Qin, C. Wang, Z. Yao et al., "Influencing factors and growth kinetics analysis of carbon nanotube growth on the surface of continuous fibers," Nanotechnology, vol. 45, no. 2, pp. 16-21, 2021.

[7] I. Gountas, V. Sypsa, G. Papatheodoridis et al., "Economic evaluation of the hepatitis C elimination strategy in Greece in the era of affordable direct-acting antivirals," World Journal of Gastroenterology, vol. 32, no. 2, pp. 47-53, 2019.

[8] A. Inam, J. Adamowski, J. Halbe, J. Malarda, R. Albanob, and S. Prasher, "Coupling of a distributed stakeholder-built system dynamics socio-economic model with SAHYSMOD for sustainable soil salinity management Part 2: model coupling and application," Journal of Hydrology, vol. 551, pp. 278-299, Article ID S0022169417301865, 2017.

[9] Y. Zhang, W. Xiang, J. Dong, and W. Wang, “An improved car-following model considering forecast speed difference with delay time," Modern Physics Letters B, vol. 33, no. 33, Article ID 1950414, 2019.

[10] Z.-X. Wang, Q. Li, and L. L. Pei, "A seasonal GM(1,1) model for forecasting the electricity consumption of the primary economic sectors," Energy, vol. 154, no. 1, pp. 522-534, 2018.

[11] Z.-c. Yang, "Predictive modeling of hourly water-level fluctuations based on the DCT least-squares extended model," Water Resources Management, vol. 32, no. 3, pp. 1117-1131, 2018.

[12] D. Liu, T. Zhang, W. Wang et al., "Two-stage physical economic adjustable capacity evaluation model of electric vehicles for peak shaving and valley filling auxiliary services," Sustainability, vol. 13, no. 15, 8153 pages, 2021.

[13] C. Zheng, S. Chen, and Z. Dong, "Economic fluctuation, local government bond risk and risk-taking of city commercial banks," Sustainability, vol. 13, 2021.

[14] J. Wang and D. Hicks, "Detecting structural change in university research systems: a case study of British research policy," Research Evaluation, vol. 22, no. 4, pp. 258-268, 2013.

[15] D. Wang, Y. Wang, Z. Huang, and R. Cui, "Understanding the resilience of coal industry ecosystem to economic shocks: influencing factors, dynamic evolution and policy suggestions," Resources Policy, vol. 67, Article ID 101682, 2020.

[16] Y. Liu, W. Lu, H. Wang, X. Gao, and Q. Huang, "Improved impact assessment of odorous compounds from landfills using Monte Carlo simulation," The Science of the Total Environment, vol. 648, pp. 805-810, 2018.

[17] A. Zoia, C. Jouanne, P. Siréta, P. Leconte, G. Braoudakis, and L. Wong, "Analysis of dynamic reactivity by Monte Carlo methods: the impact of nuclear data," Annals of Nuclear Energy, vol. 110, pp. 11-24, 2017.

[18] S. Züst, R. Züst, V. Züst, S. West, O. Stoll, and C. Minonne, “A graph based Monte Carlo simulation supporting a digital twin for the curatorial management of excavation and demolition material flows," Journal of Cleaner Production, vol. 310, Article ID 127453, 2021.

[19] H. Zaroni, L. B. Maciel, D. B. Carvalho, and E D O. Pamplona, "Monte Carlo Simulation approach for economic risk analysis of an emergency energy generation system," Energy, vol. 172, no. 1, pp. 498-508, 2019.

[20] T. Knoke, E. Gosling, D. Thom, C. Chreptun, A. Rammig, and R. Seidl, "Economic losses from natural disturbances in Norway spruce forests - a quantification using Monte-Carlo simulations," Ecological Economics, vol. 185, Article ID 107046, 2021.

[21] D. L. Zheng, L. J. Yu, and L. Z. Wang, "A techno-economicrisk decision-making methodology for large-scale building energy efficiency retrofit using Monte Carlo simulation," Energy, vol. 189, Article ID 116169, 2019.
[22] L. Y. Cheng and L. I. Jin-Kai, "Differentiated and Multi-Timepoint Impact Effect of the International Oil Price on Economic Fluctuations in China Based on TVP-VAR Model," Systems Engineering, 2018.

[23] J. Tian and Y. Liu, "Research on total factor productivity measurement and influencing factors of digital economy enterprises," Procedia Computer Science, vol. 187, pp. 390395, 2021.

[24] Y. Zhang, F. Zhao, J. Zhang, and Z. Wang, "Fluctuation in the transformation of economic development and the coupling mechanism with the environmental quality of resource-based cities - a case study of Northeast China," Resources Policy, vol. 72, no. 1, Article ID 102128, 2021.

[25] P. C. Torres, C. Morsello, L. Parry, and R. Pardini, "Forest cover and social relations are more important than economic factors in driving hunting and bushmeat consumption in post-frontier Amazonia," Biological Conservation, vol. 253, Article ID 108823, 2021.

[26] G. Chen, "Association between economic fluctuations and road mortality in OECD countries." The European Journal of Public Health, vol. 24, no. 4, pp. 612-614, 2014.

[27] B. Higgins, "The dynamics of business cycles: a study in economic fluctuations by T. Jan and Polak J. J.. Chicago: University of Chicago Press \$5.50.” European Physical Journal $C$, vol. 71, no. 71, 13 pages, 1950 .

[28] G. Horsnell, J. Jacob, and V. Duijn, “An inter-regional model of economic fluctuations," Journal of the Operational Research Society, vol. 25, no. 4, pp. 661-662, 2017.

[29] C. Quan, X. Cheng, S. Yu, and X. Ye, "Analysis on the influencing factors of carbon emission in China's logistics industry based on LMDI method - ScienceDirect," The Science of the Total Environment, vol. 734, Article ID 138473, 2020.

[30] B. Rajaratnam and D. Sparks, "MCMC-based inference in the era of big data: a fundamental analysis of the convergence complexity of high-dimensional chains," Statistics, 2015.

[31] T. Lengauer, "Statistical data analysis in the era of big data," Chemie Ingenieur Technik, vol. 92, 2020. 